\title{
Ratio Determination of Solids and Voids for Traditional Malay Carvings: A Preparation for Environmental Performance
}

\author{
Noor Hanita, Abdul Majid, and Zuraini Denan
}

\begin{abstract}
Carvings in forms of openings, roof ends and walls have been incorporated as aesthetic and climatic element in the Malay traditional buildings. Determining the ratio of solids and voids on carvings elements is seen as an essential step to gain insight on the performance of carvings as a shading devices to control sunlight and air flow. The research objectives are to inventory and digitize the carvings to determine the ratio of solid and voids, and predict their performances. The carvings sampled from all states in Peninsular Malaysia are digitized using AutoCAd to determine the area of solid and void. The ratio of solid and voids ranges from 1:1 to 99:1 and the most common ratio are $3: 2$. The ratio study is a preliminary findings towards a detail study on the daylight and ventilation control in the traditional houses.
\end{abstract}

Index Terms-Carvings, climatic performance, ratio, solid and void.

\section{INTRODUCTION}

Carvings has been incorporated in the Malay traditional buildings in forms of opening designs on windows and doors, roof ends and walls. It is an identity of the Malay culture and has been assimilated to the traditional or vernacular buildings as to increase aesthetical values to the architecture. On the other hand, the inclusion of carvings has also supported the idea that The Malay traditional house design is a manifestation of designing with the local climate [1]-[4]. The houses are designed with strategies and sunshading devices to handle and take advantage of the climate conditions. The open plan interiors with high ceiling and roof are enhanced with perforated panels that facilitates ventilation and daylighting into the interiors. The perforated panels or carvings are cut out (ukiran tebuk tembus) panels that are normally used on gables or tebar layar and partition panels (on top of windows, doors and walls or lubang angin). The carvings environmentally functioned to create a liveable and comfortable spaces within the traditional houses through allowances of daylighting penetration and ventilation [5].

Carvings are interpretations of the carvers (pengukir) from elements from the surrounding environment. It is reflected in the names given to the carving motifs; itik pulang petang, kepala cicak, tampok manggis, bunga tanjung (Mimusops elengi), bunga cempaka (Michelia champaka), bunga tikam

Manuscript is received January 25, 2014; revised May 8, 2014. This work was funded by Exploratory Research Grant Scheme (ERGS) by Ministry of High Education (Project ID ERGS13-010-0043), Malaysia.

The authors are with the Department of Architecture, Kulliyyah of Architecture and Environmental Design, International Islamic University Malaysia (e-mail: noorhanita@gmail.com; zurainidenan@gmail.com). seladang (Vallaris glabra), ketumbit, bunga teratai (Nelumbium nucifera) and ketam guri and etc. The names of the listed motifs are associated to animals and flowers which suggest the inspirations source of the carvers. These motifs has been used in decorative panels (e.g. as part of the opening designs on windows and doors), roof ends and walls [6]. Noor Hanita et al. [2] and [7] have theoretically discussed the effectiveness of the Malay vernacular design strategies in response to the climate. Nevertheless, its incorporation and effectiveness havenever been tested. Has the inclusion of the design responded to aesthetics or climatic needs; or both?

Determining the ratio of solids and voids carvings is a preliminary study to gain insights on the performance of the shading devices. This degree of effectiveness of the sun shading devices can be determined by testing the proportions and geometry of the elements employed. The performance of the sun shading devices in allowing the penetration of daylight to the interior areas will affect the thermal comfort, daylighting and ventilation inside the houses. This study is providing a new platform for exploration, experimentation and discussion of carvings that commonly covers typology, configuration and theories [2], [4]-[6], [8], [9].

\section{AIMS AND OBJECTIVES}

The research aims to determine the ratio of solid and voids in the carvings of the sunshading devices to predict and test their effectiveness. The research objectives are to inventory various types of carvings applications in the traditional buildings, categorize them into typologies, digitize them to determine the ratio of solid and voids and finally predict their performances through the ratio attained. It is expected that the experiments on the sun shading devices will substantiate the theories that the sun shading devices are effective methods to ameliorate and control the climate.

\section{Methodology}

The research starts with inventory phase through primary (from site visits) and secondary data (from KALAM and research papers) collection which covered samples from all states in Peninsular Malaysia. A total of 159 carvings units of the sunshading devices are digitized and catalogued. The carvings are digitized using AutoCAD to determine the ratio of solid and voids. The result of ratio calculation are compared between the different sun shading elements in buildings to predict the performance of the sunshading devices in allowing daylight and air penetration into the 
buildings.

The sunshading devices are categorized into three types of carving elements; roof ends, openings and wall panels (Fig 1). The categorization are generalized to the three different components that has the maximum effect on sunshading as oppose to looking at the design configurations of these carved panels for technical and aesthetical appreciation. Zumahiran and Ismail has categorized the carving panels into 12 types in their discussion on configuration and layout pattern of carvings focusing on the east coast region of Peninsula Malaysia [8]. On the other hand this study discusses the three mentioned categories with samples retrieved from randomly selected carvings from the states in Peninsular Malaysia.

Roof Ends are the carved fascia boards that overhangs beyond the walls; Wall Panels are the horizontal panels that span along the top of the walls (located just below the roof) and the carvings above the windows are categorized as Openings. The roof end is the first stage of filtration before the daylight reaches the walls where the wall panels and openings are positioned.

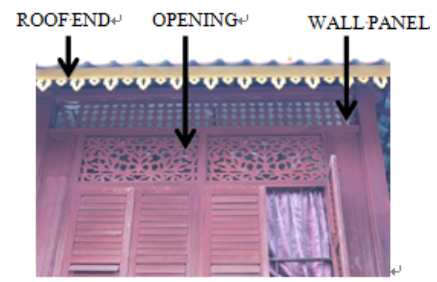

Fig. 1. Three types of carvings elements.

\section{RESUlTS AND ANALYSIS}

All carvings are digitized using AutoCAD and the area calculation of solids and voids are determined for each carving unit before the ratio are computed. Fig. 2, Fig. 3 and Fig. 4 shows the example of the digitized carving units for all three types of shading devices.



Fig. 2. Digitize sample of carved roof end.

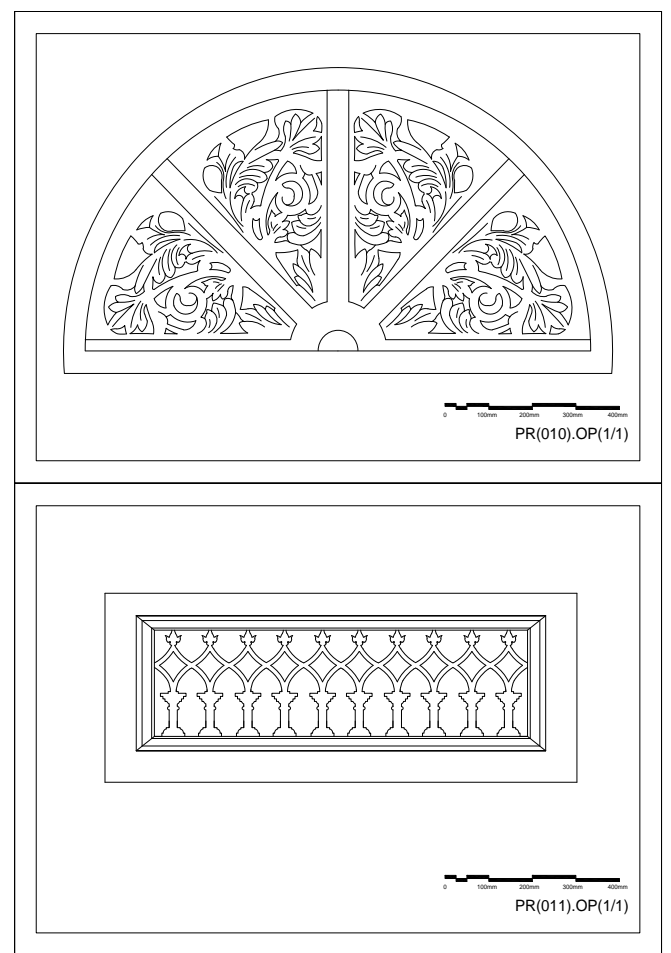

Fig. 3. Digitize sample of carved opening.

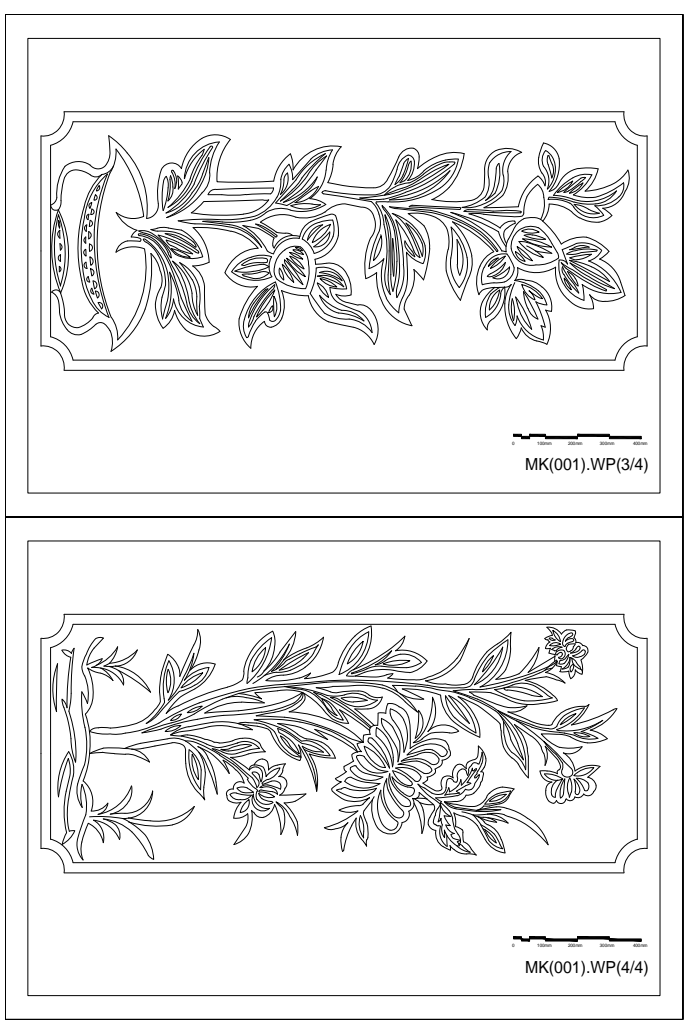

Fig. 4. Digitize sample of carved wall panel.

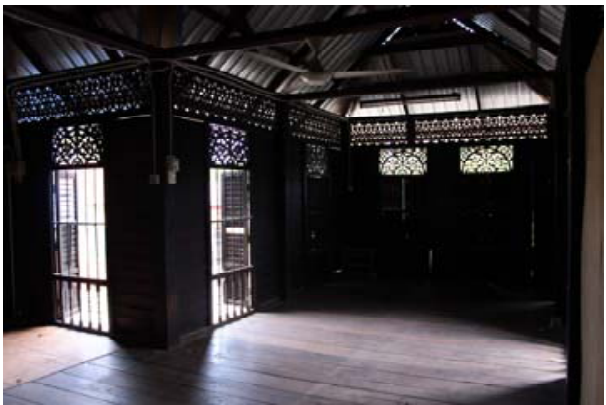

Fig. 5. The filteration of daylight to the interior space in a Malay traditional house. 
As mentioned earlier the carving panels are propagated as the devices that are incorporated to facilitate daylighting and ventilation to the interior spaces. The cut out technique enhance the filteration of daylight and allow for ventilation into the interior spaces. Fig. 5 illustrates the filteration of daylight to the interior space in a Malay traditional house. The filteration results to reduction of glare from direct sunlight but offers lighting into the interior space. As fixed panels, the carving units offers ventilation to the interior spaces at all times. Fig. 6 shows the digitized carvings for openings shown in Fig. 5.

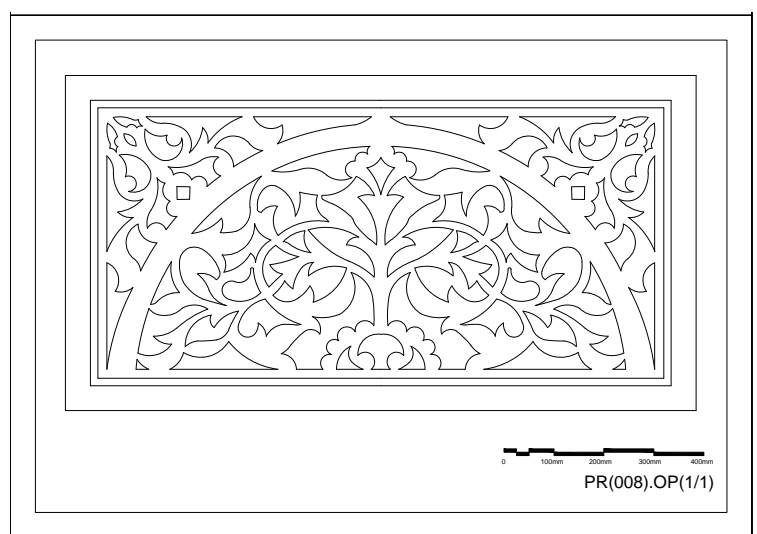

Fig. 6. The Digitized representation of the carvings in Fig. 5 of 3:2 ratio of solid and voids.

The results of ratio in all types are depicted in the Fig. 7. In all carving units, the ratio of solids are more than the voids. This is understood as the carving units are solid panels carved in ukiran tebuk (cut out carvings). The area calculated for the solid and void are converted into percentages. The ratio of solid and voids ranges from a maximum of 1:1 to 99:1 (Table I) in the inventoried units and the most common ratio of solid and void in the inventoried samples are 3:2 (Fig. 8).

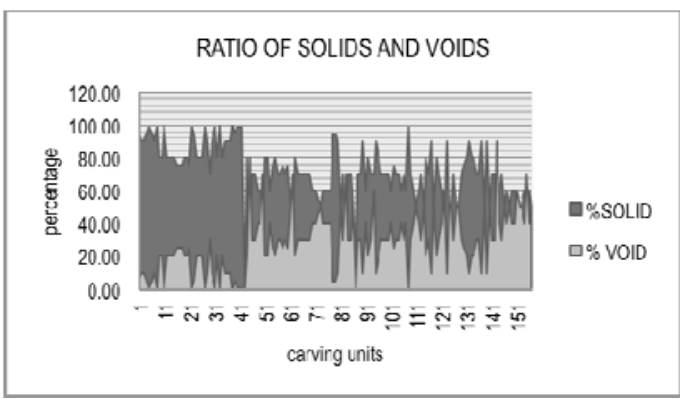

Fig. 7. Ratio of solid and void of the carving units.

TABLE I: THE MAXIMUM AND MINIMUM RATIO OF SOLID AND VOID IN SELECTED SAMPLES

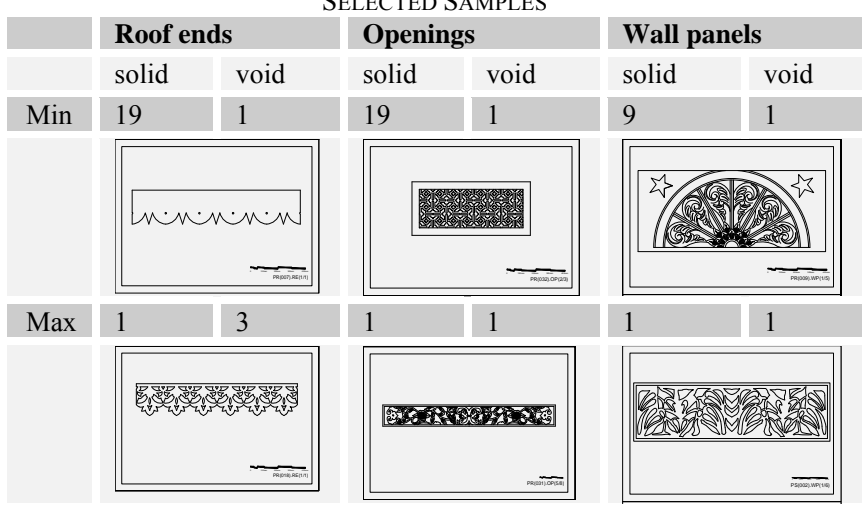

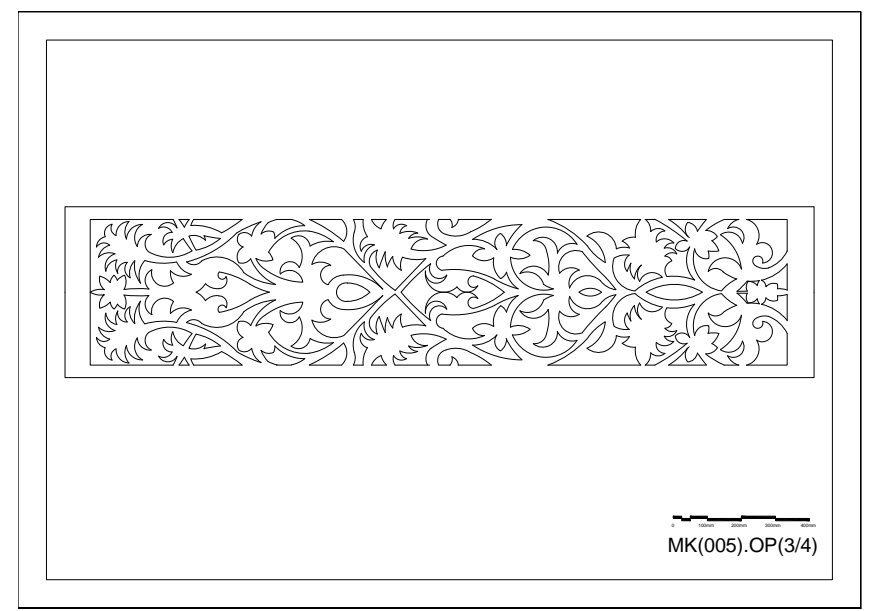

Fig. 8. An example of carving unit of the most common ratio of 2:3.

\section{CONCLUSION}

Determining the ratio of solids and voids of carvings provided the preliminary data to further study the performance of the shading devices. The different ratio of solids and voids in the carving units suggested different allowances or admittance of daylight and ventilation into the interior of the traditional buildings. The maximum ratio allows for maximum admittance that in turn will effect the thermal comfort and daylighting conditions of the interior spaces. Empirical studies by field study or computer simulations can verify the quantity of admittance and the effect of the penetration to the interior spaces. Although the determination of ratio in this paper is a preliminary study, it is unquestionably an essential phase and basis for the further empirical studies. In addition, the ratio of solid and void is a new findings to the traditions of carvings that have been produced from aesthetic appreciation and creative instincts of the carvers (pengukir).

\section{ACKNOWLEDGMENT}

The paper is written based on the works done from Exploratory Research Grant Scheme (ERGS) research grant from the Ministry of Higher Education Malaysia.

\section{REFERENCES}

[1] J. Y. Lim, The Malay House: Rediscovering Malaysia's Indigenous Shelter System, Malaysia: Institut Masyarakat, 1987.

[2] H. Zulkifli, Pola-Pola Hiasan Di Dalam Bangunan Tradisional Melayu, Dewan Bahasa dan Pustaka, 2000.

[3] A. M. N. Hanita, "State of the art presentation: indoor environment national affordable quality housing research programme," presented at National Affordable Quality Housing Research Seminar, Kuching, Sarawak, 2002.

[4] M. R. M. Tajuddin, "The discontinued traditions of Malay wood carvings in modern and post-modern architecture in Malaysia: A failure to develop the discourse on ornamentation in architectural works," Journal Alam Bina, vol. 8, no. 2, pp. 61-91, 2006

[5] C. A. Sufian and A. R. M. Sabrizaa. An Analysis of the Traditional Malay Architecture as Indicators for Sustainability: An introduction to Its Genius Loci. [Online]. Available: http://www.academia.edu/933831/

[6] A. R. M. Sabrizaa and C. A. Sufian. Malay Wood Carvings, Ornamentations and the Aesthetical Elements of the Traditional Malay Architecture. [Online] Available: http://perak.uitm.edu.my/kutai/images/present_paper/malay\%20wood $\% 20$ carving\%20and\%20ornamentations.pdf

[7] A. M. Noor Hanita, A. R. Zaiton, and D. Zuraini, "Climate responsive strategies versus the cultural and religious dimensions in the 
architecture of Malay traditional house," in Malay Vernacular Architecture: Traditional And Contemporary Expressions, M. N. Norwina, Ed. IIUM Press, 2011, Kuala Lumpur, pp. 59-70.

[8] K. Zumahiran and S. Ismail, "Configuration of carved components and its layout patterns in malay timber houses," International Journal of Architectural Research, vol. 5, no. 1, pp. 7-21, March 2011.

[9] A. R. M. Sabrizaa and C. A. Sufian, "The traditional malay architecture: between aesthetics \& symbolism," in Proc. Seminar on Intellectual Property and Heritage Issues in Built Environment, Kuala Lumpur, 2021st July, 2008.

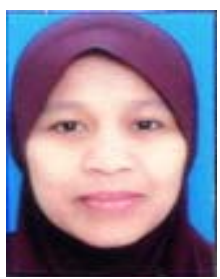

Zuraini Denan is an assistant professor at the Department of Architecture, Kulliyyah of Architecture and Environmental Design, International Islamic University of Malaysia, Kuala Lumpur. She received her bachelor of architecture degree from Texas Tech University, Texas, USA and master degree (MArch) from Universitoi Teknologi Malaysia, Skudai, Johor, Malaysia. Her $\mathrm{PhD}$ work is from the Cardiff University where she studied visual comfort (window and lighting under daylight of office buildings in hot humid country).

She involves in the review of the Malaysian Standard 2012 under the Department of Malaysian Standard (sirim 2011-2012). She is also a member of passive design group of the Japan society for the promotion of science-vice chancellors' council Of National Universities in Malaysia (jsps-vcc, 200-2009). She involves herself in advising on the daylighting issues at Kuala Lumpur Airport 2 under EAG consulting sdn bhd. Her research interests include environment ( window, daylighting and visual comfort), architectural heritage and culture and human behavior.



Noor Hanita Abdul Majid is an assistant professor at the Department of Architecture, Kulliyyah of Architecture and Environmental Design, International Islamic University of Malaysia, Kuala Lumpur. She completed her bachelor and master degrees in the field of architecture at University of Nebraska-Lincoln, USA. Her PhD work is from the University of Teknologi Malaysia where she studied outdoor thermal comfort of urban plazas. She is a receiver of research awards, i.e Veritas Research Award and Kajima Foundation, Japan and is actively involved in researches besides teaching.

Dr. Noor Hanita is currently involved in researches on passive and sustainable architecture, culture and behaviour, open spaces, housing and heritage buildings. She was involved in affordable housing design at a national level and also some international consultancy works in Makkah and Oman. 